Tsutomu Oshima MD, Kenzo Kashiki MD*, Hidenori Toyooka MD, Akio Masuda MD, Keisuke Amaha MD

\title{
Cutaneous ionto- phoretic application of condensed lidocaine
}

The purpose of this study was to determine whether iontophoretic application of high concentrations of lidocaine, with the same current, would produce cutaneous local anaesthesia rapidly enough for clinical practice. Twenty healthy volunteers, 17 male and three female, were selected for study. After fiveminute or ten-minute iontophoresis using lidocaine 4, 10, 20, $30,50 \%$, we assessed the response to pin prick with a 27-gauge sterile needle inserted to the depth of $2 \mathrm{~mm}$ at five random locations in the iontophoretically-stimulated area. Also, plasma lidocaine concentrations were measured in the venous blood samples which had been taken from three male subjects, at 3, 10, and 30 min after iontophoresis with lidocaine $50 \%$. The pain score after five-minute iontophoresis was higher than that after ten-minute iontophoresis, using each concentration of lidocaine $(P<0.001)$, whereas the pain scores had no correlation with lidocaine concentration within five-minute and ten-minute iontophoresis groups, respectively ( $P: N S$ ). On the other hand, plasma lidocaine concentration was $<1.0 \mu \mathrm{g} \cdot \mathrm{ml}^{-1}$ in all samples. No side effects other than erythema were observed afier iontophoresis using high concentrations of lidocaine up to $50 \%$. These results showed that by increasing the lidocaine concentration of the applied solution up to 50\%, the application time of iontophoresis cannot be reduced from ten to five minutes without losing analgesic effect, although iontophoresis itself can be performed with safety.

\section{Key words}

ANAESTHESIA: delivery;

ANAESTHETICS, LOCAL: lidocaine.

From the Department of Anaesthesiology and Critical Care Medicine, School of Medicine, Tokyo Medical and Dental University, 1-5-45 Yushima, Bunkyo-ku, Tokyo 113, Japan, and the *Department of Anaesthesia, Hakodate City Medical Association Hospital, 2-10-10 Tomioka-cho, Hakodate-shi, Hokkaido 041, Japan.

Address correspondence to: Dr. Tsutomu Oshima, Department of Anaesthesiology and Critical Care Medicine, School of Medicine, Tokyo Medical and Dental University, 1-5-45 Yushima, Bunkyo-ku, Tokyo 113 Japan.

Accepted for publication 28th April, 1994.
Cette étude vise à évaluer en clinique la rapidité de l'anesthésie cutanée produite par lionophorèse de hautes concentrations de lidocaïne. Vingt volontaires en bonne santé, 17 hommes et trois femmes sont recrutés pour cette étude. Après cinq ou dix minutes dionophorèse utilisant de la lidocaïne 4 , $10,20,30,50 \%$, nous évaluons la réponse à la piqûre produite avec une aiguille $27 G$ stérile insérée à $2 \mathrm{~mm}$ de profondeur à cinq endroits randomisés dans une région stimulée par ionophorèse. De plus, nous mesurons la concentration plasmatique de lidocaïne dans les échantillons de sang veineux prélevés chez trois sujets de sexe masculin à 3,10 et 30 min après ionophorèse avec de la lidocaïne 50\%. Le score de douleur mesuré sur l'échelle de la douleur après cinq min d'ionophorèse est plus élevé qu'après dix min, avec chaque concentration de lidocaïne $(P<0,001)$; il n'y a pas de corrélation entre les scores et les concentrations à lintérieur des groupes dionophorèse à cinq et dix minutes respectivement. La concentration de lidocaine est $<1,0 \mu \mathrm{g} \cdot \mathrm{ml}^{-1}$ dans tous les échantillons. Ces résultats montrent qu'en augmentant la concentration en lidocaïne de la solution jusquả $50 \%$, la durée d'application ne peut être réduite de dix à cinq minutes sans perte d'analgésie, bien que lïonophorèse elle-même ne présente pas de danger.

Iontophoresis is defined as the delivery of ions for therapeutic purposes by means of direct electrical current. In anaesthetic practice, iontophoretic application of local anaesthetics into the ear drum prior to myringotomy ${ }^{1}$ and upon the skin before vascular cannulation ${ }^{2,3}$ have been attempted instead of subcutaneous injection. Compared with administration by syringe and needle, iontophoresis should be accepted more easily by patients, particularly children, because the fear of administration is eliminated. ${ }^{3}$ However, iontophoresis to the skin has not become popular in spite of such advantages over subcutaneous injection. Gangarosa $e t$ al. suggested that profound local anaesthesia of the skin could be achieved by ten-minute iontophoresis of lidocaine hydrochloride (lidocaine), ${ }^{4}$ but ten minutes may be too long to wait in clinical practice.

The solutions applied for iontophoresis were usually lidocaine $2-4 \%:^{4}$ more concentrated solutions, $>20 \%$, have never been applied by iontophoresis. ${ }^{2}$ The purpose of this study was to determine whether iontophoretic ap- 
TABLE Subjective pain scores after five-minute and ten-minute iontophoresis with various conoentrations of lidocaine.

\begin{tabular}{|c|c|c|c|c|c|}
\hline \multirow{2}{*}{$\begin{array}{l}\text { Iontophoretic } \\
\text { duration }\end{array}$} & \multicolumn{5}{|c|}{ Lidocaine concentration } \\
\hline & $4 \%$ & $10 \%$ & $20 \%$ & $30 \%$ & $50 \%$ \\
\hline $\begin{array}{l}5 \mathrm{~min} \\
10 \mathrm{~min}\end{array}$ & $\begin{array}{l}6.2 \pm 2.4 \\
2.9 \pm 2.3^{*}\end{array}$ & $\begin{array}{l}6.6 \pm 2.5 \\
2.8 \pm 2.3^{*}\end{array}$ & $\begin{array}{l}5.4 \pm 2.2 \\
2.2 \pm 1.1^{*}\end{array}$ & $\begin{array}{l}5.5 \pm 1.8 \\
2.1 \pm 1.8^{*}\end{array}$ & $\begin{array}{l}6.2 \pm 2.6 \\
1.8 \pm 1.3^{*}\end{array}$ \\
\hline
\end{tabular}

The pain score after five-minute iontophoresis was more than after ten-minutes at each concentration of lidocaine ( ${ }^{*} P<0.001$ : compared with the pain score after five-minute iontophoresis using the same solution). The pain scores had no correlation with lidocaine concentrations, in either five-minute or ten-minute iontophoresis groups ( $P$. NS). All data are represented as mean \pm SD (standard deviation).

plication of high concentrations of lidocaine, with the same current, would produce cutaneous local anaesthesia rapidly enough for clinical practice.

\section{Methods}

The protocol of this study was approved by the Ethics Committee of the university, and informed consent was obtained from all the subjects. Twenty healthy volunteers, 17 male and three female, aged 26-50 yr, were selected for study. None had excessive susceptibility to application of electric currents, cardiac pacemakers or other electrically sensitive devices, or known sensitivity to lidocaine.

The solution was lidocaine in concentrations of 4,10 , $20,30,50 \%$ in distilled water. The solutions contained methylparaben $\left(<0.8 \mathrm{mg} \cdot \mathrm{ml}^{-1}\right)$ and the $\mathrm{pH}$ was maintained between 6.1 and 6.3 by addition of hydrochloride $(\mathrm{HCl})$ and sodium hydroxide $(\mathrm{NaOH})$.

For this study, a rectifier was constructed which produced electric currents in the range 0 to $10 \mathrm{~mA}$.

\section{Experimental protocol}

The flexor surfaces of the subject's left and right forearms were used for the study. Each subject was seated with elbows rested on a table and hands elevated. A blindfold was used to cover the subject's eyes. Throughout the study, the subjects were not allowed to see their arms.

The investigator swabbed the area of the positive electrode attachment with alcohol and applied $0.3 \mathrm{ml}$ of the randomly selected solution to the paper pad on a positive electrode (approximately $10 \times 15 \mathrm{~mm}$ ). Thereafter, the investigator placed the positive electrode on the arm. The subject gripped a negative electrode (a wet bag of cloth with wool inside) with the ipsilateral hand. The electric current was quickly increased from 0 to $1.5 \mathrm{~mA}$ at which level it was maintained for five or ten minutes. At the end of the stimulation, the electrodes were removed. The anaesthetic effect was determined by assessing the response to pin prick with a 27-gauge sterile needle inserted to the depth of $2 \mathrm{~mm}$ at five random locations in the stimulated area, which were also observed for colour change.

In the course of the experiment, venous blood was taken from three male subjects, at 3,10, and $30 \mathrm{~min}$ after ten-minute iontophoresis with lidocaine $50 \%$. The venous blood samples were immediately iced and centrifuged at $3000 \mathrm{rpm}$ for $10 \mathrm{~min}$ and $0^{\circ} \mathrm{C}$. Plasma was frozen and stored in plastic tubes at $-20^{\circ} \mathrm{C}$ until analysis. Plasma lidocaine concentrations were determined using an enzyme immunoassay method (EMIT, assay range: $1.0-12.0 \mu \mathrm{g} \cdot \mathrm{ml}^{-1}$, Syva). Intraassay variations were $<12 \%$.

Subjective pain was graded by comparing the pain to pin prick in the stimulated area with that in a nearby unanaesthetized site. A four-point scale was used:

0 - no pain

1 - reduction of pain but not complete

2 - normal pain sensation

3 - more painful than in unanaesthetized site

The sum of the grades at the five locations was regarded as the pain score. Paired Student's $t$ test was used to compare the pain scores after five-minute iontophoresis with those after ten-minute iontophoresis at each concentration of lidocaine. Analysis of variance (ANOVA) was applied to assess the relationship between pain scores and lidocaine concentrations. Differences were considered significant as $P<0.05$. All data are presented as mean \pm standard deviation (SD).

\section{Results}

The current was well tolerated in all subjects. Pain scores after five-minute iontophoresis were higher than after tenminute iontophoresis $(P<0.001)$ for each concentration of lidocaine, although the grading of sensation using the four point scale was not uniform at the five locations in the iontophoretically stimulated area. In both the fiveminute and ten-minute iontophoresis groups, the pain score had no correlation with lidocaine concentration of the applied solution ( $P$. NS) (Table). In all cases, the anaesthetized area was erythematous immediately after 
iontophoresis, but the erythema disappeared within two days.

Plasma lidocaine concentration was $<1.0 \mu \mathrm{g} \cdot \mathrm{ml}^{-1}$ in all samples. None of the subjects complained of any discomfort other than cutaneous itching at the sites on which the electrode had been placed during iontophoresis.

\section{Discussion}

The purpose of this study was to determine whether iontophoretic application of lidocaine up to $50 \%$, without increasing the electric current, would produce cutaneous local anaesthesia rapidly enough for clinical practice. However, the pain score after five-minute iontophoresis was always higher than after ten-minute iontophoresis with all concentrations of lidocaine. In other words, iontophoretic duration could not be reduced from ten to five minutes without decreasing its anaesthetic effect even if lidocaine up to $50 \%$ was applied.

The amount of the drug delivered by iontophoresis depends upon the electrical dose because iontophoretic delivery is faster than by diffusion. Thus, the electric current should be increased to reduce the application time of iontophoresis without decreasing its anaesthetic effect. However, high levels of electrical current increase the risk of cutaneous burns. The level of current depends upon the available area over which it is applied and the patient's resistance; more current can be applied over a larger area since there is greater distribution of current or lower density. The usual comfortable level is $<1.5 \mathrm{~mA}$, considering the area stimulated by iontophoresis in this experiment $(10 \mathrm{~mm} \times 15 \mathrm{~mm}) \cdot{ }^{4}$ In this study, none of the subjects suffered cutaneous burns.

The amount of drug delivered by iontophoresis de- pends, to a minor extent, upon the concentration of the applied solution because diffusion plays a minor role in iontophoretic delivery. However, Gangarosa et al. reported increased penetration of nonelectrolytes into mouse skin during iontophoresis. ${ }^{5}$ This phenomenon was caused by water transport during iontophoresis - "iontohydrokinesis." Concentrated lidocaine solutions, $>\mathbf{2 0 \%}$, have never been applied for iontophoresis. ${ }^{2}$ Therefore, there was a possibility that the iontophoretic application of more condensed lidocaine solutions could contribute to an increase in drug delivery, resulting in reduction of the iontophoretic time while maintaining its anaesthetic effect. However, this trial was not successful and this may be attributed to unchanged skin permeability during iontophoresis. $^{5}$

Hydrochloride salts of local anaesthetics have highest conductivity at a $\mathrm{pH}<5$ because this $\mathrm{pH}$ keeps almost all local anaesthetics as positively charged molecules. Increasing $\mathrm{pH}$ tends to decrease conductivity by converting positively charged molecules to unionized molecules. ${ }^{6}$ In this study, however, the effect of the $\mathrm{pH}$ on the conductivity was excluded since the $\mathrm{pH}$ of all the solutions were kept between 6.1 and 6.3 .

In this study, the grading of sensation was not uniform at the five locations, perhaps because of the difficulty in giving the uniform distribution of electric current over the contact area.

Iontophoresis is contraindicated over broken or damaged skin, but all of the subjects in this study had intact skin. Although a very high concentration of lidocaine was administered locally, the possibility of systemic toxicity is negligible since plasma lidocaine concentrations were too small to be detected. After the iontophoretic procedure, however, the applied area always showed erythema, suggesting vasodilatation, but this vanished within two days. No other side effects were observed.

In conclusion, we suggest that even if solutions with very high concentrations of lidocaine up to $50 \%$ are applied, iontophoretic application cannot be reduced from ten to five minutes without decreasing its anaesthetic effect, although iontophoresis itself can be performed with safety.

\section{Acknowledgements}

The authors are grateful to T. Sawa for the technical assistance and W. Inaba and J. Zaha for the secretarial help.

\section{References}

1 Comeau M, Brummett R, Vernon J. Local anesthesia of the ear by iontophoresis. Arch Otolaryngol 1973; 98 : 114-20.

2 Arvidsson SB, Ekroth RH, Handsby AMC, Lindholm $A H$, William-Olsson G. Painless venipuncture. A clinical trial of iontophoresis of lidocaine for venipuncture in blood donors. Acta Anaesthesiol Scand 1984; 28: 209-10.

3 Zelizer L, Regalado M, Nichter LS, Barton D, Jennings $S$, Pitt $L$. Ionotophoretic versus subcutaneous injection: a comparison of two methods of local anesthesia delivery in children. Pain 1991; 44: 73-8.

4 Gangarosa LP Sr. Defining a practical solution for iontophoretic local anesthesia of skin. Methods Find Exp Clin Pharmacol 1981; 3: 83-94.

5 Gangarosa LP, Park NH, Wiggins CA, Hill JM. Increased penetration of non-lectrolytes into mouse skin during iontophoretic water transport (iontohydrokinesis). J Pharmacol Exp Ther 1980; 212: 377-81.

6 Gangarasa LP, Park NH, Fong BC, Scou DF, Hill JM. Conductivity of drugs used for iontophoresis. J Pharm Sci 1978; 67: 1439-43. 